\title{
Choosing the wrong drivers for whole system reform
}

\author{
Michael Fullan
}

Summary of Seminar Series Paper No. 204, May 2011

(C) 2011 Centre for Strategic Education

\section{Introducing the drivers for whole system reform}

'Whole system reform' is the name of the game and 'drivers' are policy and strategy levers that have the least and best chance of driving successful reform. A 'wrong driver' is a deliberate policy force that has little chance of achieving the desired result, while a 'right driver' is one that achieves better measurable results for students. This paper examines drivers typically chosen to accomplish reform, critiques their inadequacy, and offers an alternative set that have been proven to be more effective.

I suggest four criteria to judge a driver's effectiveness. Does it

1. foster motivation of teachers and students;

2. engage educators and students in continuous improvement;

3. inspire team work; and

4. affect all teachers and students?

Intrinsic motivation, instructional improvement, teamwork, and 'allness' are the crucial elements for whole system reform.

The key to system-wide success is to place educators and students at the centre. This means aligning the goals of reform and the intrinsic motivation of participants. So policies that foster strong intrinsic motivation across the whole system are required, as are strategies that develop increased capability. Both strong motivation and enhanced skills on a large scale are required.

Two recent analyses of comparative international performances, the PISA results (OECD, 2010a), and the McKinsey report (Mourshed et al, 2010), have provided evidence on this matter. In both the PISA and McKinsey reports the top five countries in literacy, science and mathematics are Korea, Finland, Hong Kong, Singapore and Canada.

In this paper I use the United States and Australia as examples of recent ambitious national education reform initiatives. Both have acknowledged a strong sense of urgency for reform and their political leaders desire better whole system reform results as quickly as possible. Policy makers are desperate for 'drivers that work' - those that produce better results across the system.

The four 'wrong' drivers I discuss have face-value appeal for people with urgent problems. They look like plausible solutions but are 'silver bullets'. However, we will soon see breakthroughs in collective recognition of their shortcomings, for several reasons:

- evidence that the wrong drivers don't work is increasingly clear and compelling;

- there are alternative solutions that work which are also clear and compelling; and

- those most committed to reform, and most perplexed by the lack of progress, will realise why.

Effective drivers are those

- that cause whole system improvements;

- that are measurable in practice and results; and

- for which a case can be made that strategy X produces result $\mathrm{Y}$. 
An ineffective driver, however, is one that

- actually does not produce the results it seeks;

- may make matters worse; and

- can never have the impact it purports to produce.

There are four main 'wrong drivers' that have more effective matched alternatives. The pairs of alternatives are

1. accountability: using test results, and teacher appraisal, to reward or punish teachers and schools vs capacity building;

2. individual teacher and leadership quality: promoting individual vs group solutions;

3. technology: investing in and assuming that the digital world will carry the day vs instruction; and

4. fragmented strategies vs integrated or systemic strategies.

Although the four 'wrong' components have a place in reform, it is a mistake to lead with them. Countries that do will not achieve whole system reform but may move backwards relative to countries using the right drivers. Note that none of the top-performing countries led their reforms with these four current favourites. The four 'wrong drivers' are not forever wrong, they just should not be lead drivers. The four 'right drivers' are the anchors of whole system reform. Judicious use of the four right drivers will accomplish better the sought-for goals more powerfully and sustainably because they work directly on changing the culture of school systems; by contrast, the wrong drivers alter formal attributes of the system without reaching the internal substance of reform.

What binds the effective drivers together is the underlying attitude, philosophy, and theory of action. It is okay to use all eight drivers provided the right four are dominant over the less effective four.

The evidence is clear: the wrong four as drivers demotivate those people required for success; the right four do the opposite. All systems need to adopt the right drivers because this will give them success, and will result in global advances.

Let us consider the national education reforms currently being pursued in the US and Australia.

\section{The US and Australia}

The US

The Obama administration has launched a reform effort that is entitled colloquially 'race to the top' - see A Blueprint for Reform (US Department of Education, 2010a). Four pillars are seen in this system:

- new standards and corresponding assessments;

- a data system that tracks student achievement and teacher effectiveness;

- improving teacher and principal quality through recruitment, training and rewarding excellence; and

- improving the 5000 worst-performing schools.

Two consortia have been funded by the Federal Government to develop assessments for the new Common Core State Standards (CCSS). One is developing 'summative' evaluations that will be administered four times during a year for students in Grades 3-8. These will be supported by access to data with accompanying resources. The other will integrate performance tasks, computer adaptive assessments for online scoring and response, measurement of growth, and accountability reports. Another part of the reform consists of the development of updated standards for teachers and administrators. 


\section{Australia}

Australia has similar ambitions and strategies - see National Education Agreement (COAG, 2008).

Four areas of reform have received priority:

- developing a national framework of schooling;

- increasing school level transparency and accountability, to improve student and school

performance;

- closing the gap in educational outcomes between Indigenous and non-Indigenous students; and

- developing and implementing a national curriculum across all learning areas from $\mathrm{K}-12$.

As in the US, the strategy is to drive reform by better standards, assessment, monitoring, intervention and teacher development.

I believe these ambitious and admirable nationwide goals will not be met with the strategies being used. No successful system in the world has ever led with these drivers - they are ineffective because they do not change the day-to-day culture of school systems.

\section{Focusing on Accountability (vs Capacity Building)}

A focus on accountability uses standards, assessment, rewards and punishment as its core drivers. It assumes that educators will make the necessary changes to develop the skills and competencies to get better results. However, leading with accountability is not the best way to get accountability, let alone whole system reform. The four right drivers actually produce better accountability of action and results.

It is not the presence of standards and assessment that is the problem, but the attitude that underpins them, and their dominance. What is required is to build new skills and generate deeper motivation. Focusing on standards and assessments does not highlight the instructional improvements that are the core driver: it is the learning-instruction-assessment nexus that central to driving student achievement.

Accountability in the form proposed in the US and Australia does not build widespread capacity, nor does it increase intrinsic motivation. Position assessment primarily as a strategy for improvement, not as a measure of external accountability.

A major McKinsey study finding was this: in the improving systems in the developing countries there was an equal proportion of accountability and capacity-building activities; in the good-togreat countries the percentages were $78 \%$ cent professional learning and $22 \%$ accountability.

Unfortunately, the current standards-assessment imposition will squelch any possibility that higherorder skills will be accomplished, even though some of these are in the set to be taught. Application of the four wrong drivers block any possibility of heading down this path. High-stakes accountability will only motivate a small percentage of teachers and, even if motivated, only a minority will know what changes to make to get better results. Nor will turning around the bottom $5 \%$ of schools work. The whole system must improve, and in the next few years.

Transparency of results and practice will be key to securing public commitment to education and to elevating the profession. This vertical accountability is essential. However, it must be sustained by capacity building, engagement, and trust building, which produce the critical elements for wholesystem reform of greater lateral accountability among peers. 


\section{Individual Quality (vs Group Quality)}

Teacher appraisal and feedback would seem to be a good idea (CCSSO, 2011; Gates Foundation, 2010; Jensen and Reichl, 2011). This strategy is justified on the basis that feedback improves performance. But teacher appraisal will not work unless it is embedded in a school culture of learning where teachers are motivated to learn from feedback. The practice of integrating feedback into actions that result in improvement is embraced by teachers and their leaders because their culture values it. That is why it works.

No nation has got better by focusing on individual teachers as the driver. Better performing countries are successful because they developed the entire teaching profession.

A recent study (Leana, 2011) was designed to test the relationship between the power of human and social capital. Leana reports that teachers who were both more able (high human capital) and had stronger ties with their peers (high social capital) had the biggest gains in student achievement. She even found that low-ability teachers perform as well as teachers of average ability 'if they have strong social capital' in their school. Thus, high social capital and high human capital must be combined, with the former being the more powerful. Both should be developed in concert, but high social capital is a powerful strategy to leverage human capital.

Disturbingly, for those employing the wrong drivers, is that even if driver one (accountability) produces some increase in human capital, it will be swamped by the failure to pay equal attention to social capital. Thus, changing social capital is the powerful strategy.

There is a developmental sequence here. As teacher and leader capacity become stronger, peers become the greater driving force. By mobilising peers, leaders accelerate whole system reform, and establish conditions for sustainability. Every high performing system studied by the McKinsey group combined policies to attract and develop high quality teachers with strategies and incentives for leaders and peers to work together.

A major contribution to the debate about how to increase the quality of teachers and principals is an OECD report (2011) which includes the significant lesson that you must have widespread teacher ownership. If teacher quality is the premier factor related to student learning and you want whole system transformation then virtually all teachers must own the reform. All the successful systems have recognised this fact. What works is the daily experience of all teachers - peers working together in a purposeful, effective profession while embracing public accountability.

The essence of whole system success is continuous instructional improvement linked to engagement and success for all students. The drivers that work motivate teachers to engage in instructional improvement with peers. Revealingly, the reverse causal sequence is also crucial: increasing instructional improvement causes motivation to increase. Success means greater efficacy and the latter breeds greater commitment.

\section{Technology (vs Instruction)}

Ever since the first laptop emerged almost 40 years ago technology has been winning the race over pedagogy: technology gets better and better, while instruction doesn't.

There are signs that pedagogy is seeking the driver's seat. The main policy document from the US gets it right (US Department of Education, 2010b). - the essential idea is to get the right learning embedded in the technology. 
No successful country became good through using technology at the front. Without pedagogy in the lead technology may be driving us to distraction, with the child's digital world detached from the school world.

Technology will be a dramatic accelerator if we can put instruction and skilled, motivated teachers and students in the lead. Once this instructional-digital powerhouse gets under way, students will motivate teachers as much as the other way around. This is the necessary impetus to reverse the trend of technology racing ahead of pedagogy: learning and instruction will become the driving forces, so we will ride the technology wave instead of being at the mercy of a powerful, but intrinsically aimless, phenomenon.

\section{Fragmented (vs Systemic)}

Along with cultural traditions of individualism come tendencies to focus on single rather than systemic solutions. The US, for example, has a habit of breaking things into pieces: what looks like a system is not, because the pieces are not well connected.

Systemic strategies both require and support universal on-the-ground improvement efforts. This is why the 'right' sides of drivers one to three are the winners. Capacity building, group work and deep pedagogy, accelerated by technology, are processes that support all schools engaging in improvement of practice. Systemic means all elements of the system are interconnected and involved, day after day. Systemic is experiential not theoretical. Thus, the four wrong drivers are not 'systemic' by this definition.

In the successful countries there is a belief that universal quality education is crucial to their future (OECD, 2011). These countries approach the task with the knowledge that everyone must be part of the solution.

The successful systems have come to trust and respect teachers. If you don't have trust how do you get it? To break the cycle of distrust you have to respect others 'before they have earned the right to be respected' and then build competencies and trust over time.

Systemic implementation builds greater accountability into the system among teachers and others than can be obtained by more overt measures. This can be achieved in reasonable timelines - six years, the McKinsey group found - if you employ the right combination of drivers.

\section{Implications}

Focus first on the limitations of the four current policy/strategy levers that are fatal to whole system reform.

In relation to recent US and Australia reforms, it might be considered unfair to judge them before they have an impact. I argue there is no way the four 'wrong drivers' can motivate the masses, which is required for whole system reform. Moreover, we have many examples that the alternative drivers do work because they change the culture of teaching and learning.

The solution involves using the four big effective drivers:

1. The learning-instruction-assessment nexus.

2. Social capital to build the profession.

3. Pedagogy matches technology.

4. Systemic synergy. 
First, ensure the centrepiece of action is based on learning and instruction. Relentless development of 'capacity building' is the main agenda. Integral to this is commitment to the moral purpose of raising the bar and closing the gap for all students.

Second, use groups to accomplish a learning-instruction culture. Approach the solution as a social capital proposition to build the teaching profession. This requires building collaborative cultures within and across schools.

Third, power new pedagogical innovations with technology. They make education easier and more absorbing - learning and life become more seamless.

Fourth, the set of good drivers must comprise a coherent, interactive whole.

There is a choice and some countries have made it. Replace the juggernaut of wrong drivers with lead drivers that work. Key leaders make a difference at this juncture. Jettison blatant merit pay, reduce excessive testing, don't depend on teacher appraisal as a driver, and don't treat world-class standards as a panacea. Instead, make the instruction-assessment nexus the core driver, and support this with a system that mobilises the masses to make the moral imperative a reality.

\section{References}

CCSSO (2011) Model Core Teaching Standards: A Resource for State Dialogue, Council of Chief State School Officers, Washington, DC.

COAG (2008a) National Education Agreement, Council of Australian Governments, Canberra.

Gates Foundation (2010) Learning About Teaching: Initial Findings from the Measures of Effective Teaching Project, Gates Foundation, Redmond, WA.

Jensen, B and Reichl, J (2011) Better Teacher Appraisal and Feedback: Improving Performance, Grattan Institute, Melbourne.

Leana, C (2011) 'An open letter to Bill and Melinda Gates on the value of social capital in school reform', Stanford Social Innovation Review (Draft, 28 February 2011).

Mourshed, M, Chinezi, C and Barber, M (2010) How the World's Most Improved School Systems Keep Getting Better, McKinsey and Company, London.

OECD (2010) Programme for International Student Assessment (PISA) 2009, Organisation for Economic Cooperation and Development, Paris. Accessed 18 April 2011 at www.oecd.org/pages/0,3417, en_32252351_32236225_1_1_1_1_1,00.html.

OECD (2011) Building a High-quality Teaching Profession: Lessons from Around the World, Organisation for Economic Cooperation and Development, Paris.

US Department of Education (2010a) A Blueprint for Reform, US Department of Education, Washington, DC.

US Department of Education (2010b) Learning Powered by Technology, US Department of Education, Washington, DC. 